\title{
Direct detection of ammonium ion by means of oxygen electrocatalysis at a copper-polyaniline composite on a screen-printed electrode
}

\author{
Mykhailo T. Zhybak ${ }^{1,2}$ - Mikhail Yu. Vagin ${ }^{2,3} \cdot$ Valerio Beni $^{4} \cdot$ Xianjie Liu $^{2}$. \\ Eithne Dempsey $^{5} \cdot$ Anthony P. F. Turner $^{2} \cdot$ Yaroslav I. Korpan $^{1}$
}

Received: 14 January 2016/Accepted: 14 March 2016 / Published online: 29 March 2016

(C) Springer-Verlag Wien 2016

\begin{abstract}
We describe a composite material for use in electrochemical oxygen reduction. A screen-printed electrode (SPE) was consecutively modified with electrodeposited copper, a Nafion membrane and electropolymerized polyaniline (PANi) to give an electrocatalytic composite of type $\mathrm{PANi} / \mathrm{Nafion} / \mathrm{Cu}_{2} \mathrm{O} / \mathrm{SPE}$ that displays good electrical conductivity at neutral $\mathrm{pH}$ values. It is found that the presence of ammonia causes complex formation with $\mathrm{Cu}(\mathrm{I})$, and this causes electroreduction of oxygen to result in an increased cathodic current. The finding was applied to the quantification of ammonium ions in the 1 to $1000 \mu \mathrm{M}$ concentration range by amperometry at $-0.45 \mathrm{~V}$ (vs. $\mathrm{Ag} / \mathrm{AgCl}$ ). This Faradaic phenomenon offers the advantage of direct voltammetric detection, one of the lowest known limits of detection $(0.5 \mu \mathrm{M})$, and high sensitivity $\left(250 \mathrm{~mA} \mathrm{M}^{-1} \mathrm{~cm}^{-2}\right)$. It was applied to the determination of ammonium ion in human serum where it
\end{abstract}

Electronic supplementary material The online version of this article (doi:10.1007/s00604-016-1834-3) contains supplementary material, which is available to authorized users.

Mikhail Yu. Vagin mikva@ifm.liu.se

$\triangle$ Yaroslav I. Korpan

korpan@imbg.org.ua

1 Institute of Molecular Biology and Genetics, NAS of Ukraine, Kyiv 03680, Ukraine

2 Department of Physics, Chemistry and Biology, Linköping University, -581 83 Linköping, SE, Sweden

3 Laboratory of Organic Electronics, Department of Science and Technology, Linköping University, -601 74 Norrköping, SE, Sweden

4 ACREO Swedish ICT, -601 74 Norrköping, SE, Sweden

5 Centre for Research in Electroanalytical Technologies, Department of Science, Institute of Technology Tallaght, Tallaght, Dublin, Ireland compared well with the photometric routine approach for clinical analysis using glutamate dehydrogenase.

Keywords Conductive polymer $\cdot$ Nanocomposite . Amperometry · Electrochemical impedance spectroscopy · SEM $\cdot$ EDX $\cdot$ XPS $\cdot$ Serum analysis

\section{Introduction}

Ammonium ions are an essential part of the nitrogen cycle and the metabolic product of many substances [26]. As one of the waste product of the metabolism of animals, ammonium ions are of great biological importance [14]. Thus, monitoring of ammonium ion content of clinical and environmental samples is clearly important.

Among the different approaches for the ammonium ion quantification [24], electrochemical detection offers the possibility of real-time monitoring in combination with the advantages of low cost, high sensitivity and selectivity, and independence of the sample color and turbidity. A variety of ammonium ion-selective electrodes has been developed [19]. To overcome most of the obstacles faced by potentiometric assays a number of laboratory prototypes of amperometric ammonium sensors have been developed with ion-selective components [23] and enzymes [3].

Polyaniline (PANi) deposited on gold or platinum electrodes in association with negatively charged polyelectrolytes matrices, is robust, has high conductivity at room temperature and is very sensitive to ammonium ions [5]. However, PANiNafion composites formed on glassy carbon showed significantly lower sensitivity [7]. Hence, the mechanistic aspects of the amperometric detection of ammonium ions at conductive polymers are still unclear. 
The sluggish kinetics of the oxygen reduction reaction (ORR) is considered to be a major limiting factor in oxygenassociated energy conversion [27] in fuel cells. Precious metals are the most active catalysts for the ORR, $s$ but have the serious drawbacks of high costs and susceptibility to poisoning. Considerable efforts have been expended on the development of non-precious metal catalysts, which can operate in the neutral media required for bacterial fuel cells. Conductive polymers are considered a viable alternative as inexpensive conductive catalysts for ORR, because of they have significant conductivities, operate in neutral media of microbial fuel cells [29] and are a source of heteroatoms $[20,28]$.

We report the incorporation of copper into a PANi-Nafion composite to achieve ammonia-associated electrocatalysis of the ORR. The composite was utilized for direct quantification of ammonium. Consecutive film formation was monitored using electrochemical methods and surface characterization techniques. The appearance of a cathodic current in the presence of ammonium ions was used for ammonium quantification in human serum.

\section{Experimental}

\section{Materials}

Copper nitrate, $5 \%$ Nafion ${ }^{\circledR}$ perfluorinated resin solution, hydrochloric acid, nitric acid, sodium chloride, $\mathrm{KH}_{2} \mathrm{PO}_{4}$, $\mathrm{Na}_{2} \mathrm{HPO}_{4}$, aniline (99\%) ethanol, urea, creatinine (anhydrous), bovine serum albumin (BSA) (fraction V, $96 \%$ ) were purchased from Sigma-Aldrich (Germany; www.sigmaaldrich. com). Aniline was redistilled before use. Ammonium chloride was purchased from Fluka (www.sigmaaldrich.com). All the chemicals and solvents used were of analytical-reagent grade and used without further purification.

$20 \mathrm{mM}$ phosphate buffer (prepared by mixing and diluting $20 \mathrm{mM}$ disodium hydrogen phosphate, $20 \mathrm{mM}$ potassium dihydrogen phosphate and $20 \mathrm{mM}$ sodium chloride) $\mathrm{pH} 7.4$, was used as the supporting electrolyte during all the electrochemical measurements. All solutions were prepared using 18.2 $\mathrm{M} \Omega \cdot \mathrm{cm}$ purified water produced using a Simplicity water purification system from Millipore (www.merckmillipore. com). All glassware and polyethylene materials were rinsed with ultrapure water and dried before use.

\section{Apparatus and procedures}

\section{Electrochemical measurements}

Electrochemical experiments were carried out using a portable potentiostat $\mu$ Stat 400 DropSens (Spain, www.dropsens.com) and screen-printed electrodes (SPE), consisting of an integrated working electrode (diam. $4 \mathrm{~mm}$ ), a carbon counter electrode and an $\mathrm{Ag} / \mathrm{AgCl}$ reference electrode (C110, DropSens, Spain). All electrochemical measurements were performed at room temperature and in the presence of chloride ions in the supporting electrolyte.

\section{Electrode modification with PANi-nafion-Cu composite}

A Cu-modified SPE was prepared by cyclic voltammetry in $0.05 \mathrm{M}$ copper (II) nitrate solution in $0.1 \mathrm{M} \mathrm{HNO}_{3}$ (from $-0.9 \mathrm{~V}$ to $0.7 \mathrm{~V}, 50 \mathrm{mV} \mathrm{s}^{-1}, 10$ cycles). Then the $\mathrm{Cu}$ modified SPE was rinsed thoroughly with water and modified with Nafion ( $2 \mu \mathrm{L}$ of $2 \mathrm{wt} \%$ solution air-dried for $15 \mathrm{~min}$ ). The PANi polymerization was performed by cyclic voltammetry in $0.2 \mathrm{M}$ aniline solution in $0.5 \mathrm{M} \mathrm{HCl}(-0.4 \mathrm{~V}$ to $1.0 \mathrm{~V}$, $50 \mathrm{mV} \mathrm{s}^{-1}, 10$ cycles). The PANi-Nafion-Cu-modified SPE was then rinsed thoroughly with distilled water and dried in air for $15 \mathrm{~min}$. Prior to use, the electrodes were soaked in phosphate buffer for $30 \mathrm{~min}$ at room temperature to equilibrate the sensing composite. The sensor response to ammonium ion concentration was taken as the average of three separate measurements.

\section{Surface analysis}

The surface morphology of the modified electrode surface at all stages was examined using SEM (JEOL JSM 6390 LV) over a range of magnifications and accelerating voltages (both backscattered and secondary images). The identity of each element in all the samples was confirmed by EDX. Photoemission experiments were carried out using a Scienta ESCA 200 spectrometer in ultrahigh vacuum with a base pressure of $10^{-10}$ mbar. The measurement chamber was equipped with a monochromatic $\mathrm{Al}$ (K alpha) X-ray source providing photons with $1486.6 \mathrm{eV}$ for XPS (X-ray photoemission spectroscopy). The XPS experimental condition was set so that the full width at half maximum of the clean $\mathrm{Au} 4 \mathrm{f} 7 / 2$ line was $0.65 \mathrm{eV}$. All spectra were collected at a photoelectron takeoff angle of $0^{\circ}$ (normal emission) at room temperature.

\section{Ammonium quantification in human serum}

Venous blood $(2 \mathrm{~mL})$ was collected in heparinised cold tubes from healthy volunteers and patients with chronic kidney and liver diseases (Kyiv Research and Practice Center of Nephrology and Hemodialysis, Ukraine). The tubes were centrifuged at $1500 \mathrm{~g}$ for $10 \mathrm{~min}$ and cell-free supernatant removed. All serum samples were kept cold in an ice box during the time between collection and measurement. The assay of ammonium in the serum samples was performed by amperometry at $-0.45 \mathrm{~V}$ in unstirred solution. An aliquot of the serum sample was directly injected into the measuring vessel in order to obtain a 100-500 fold dilution. Reference data on ammonium concentration were obtained from a 
commercial laboratory by the standard colorimetric assay (glutamate dehydrogenase with $\alpha$-oxoglutarate and $\mathrm{NAD}(\mathrm{P}) \mathrm{H})$.

\section{Results and discussions}

\section{Composite assembly}

Figure 1a shows the voltammetric response obtained on continuously cycling in solutions of $\mathrm{Cu}^{2+}$ nitrate. The cathodic currents observed at the starting potential of $-0.9 \mathrm{~V}$ represent the formation of reduced copper compounds onto the
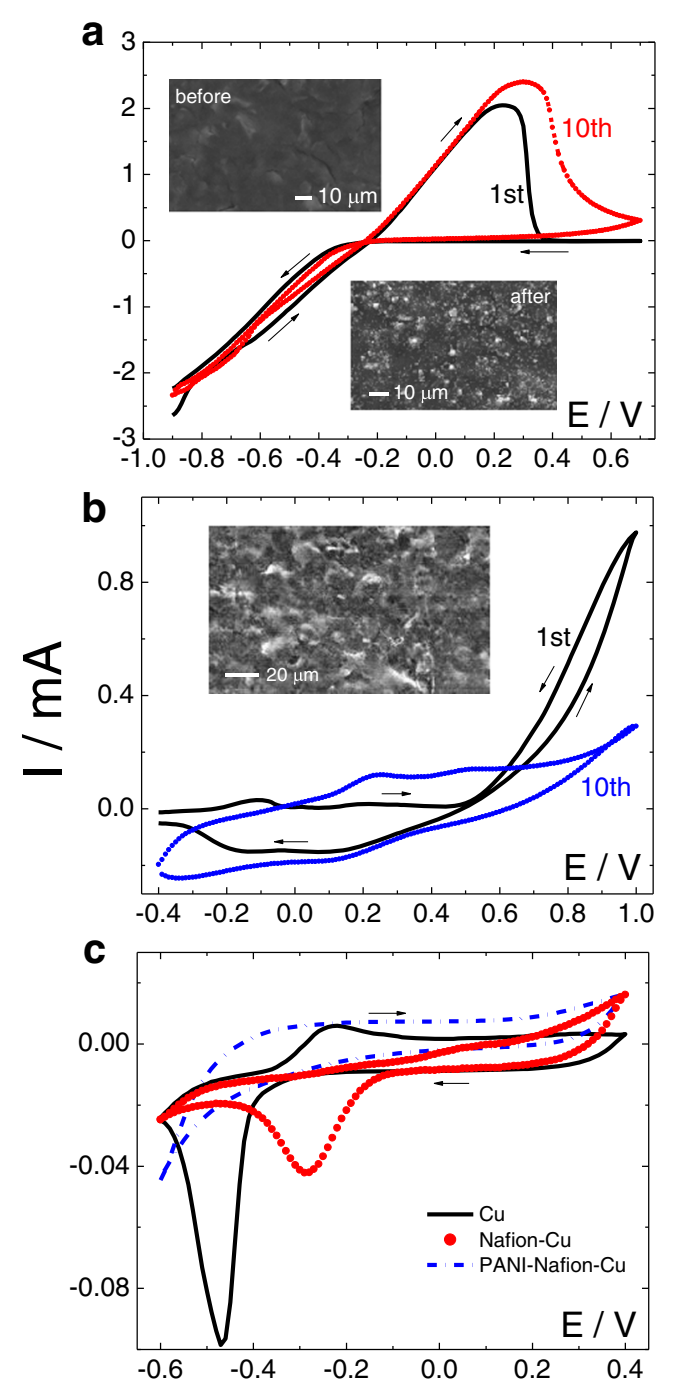

Fig. 1 Preparation of PANi-Nafion-Cu composite on a SPE surface. a: modification by $\mathrm{Cu}_{2} \mathrm{O}\left(0.1 \mathrm{M} \mathrm{HNO}_{3}, 50 \mathrm{mM} \mathrm{Cu}\left(\mathrm{NO}_{3}\right)_{2}\right.$, scan rate $50 \mathrm{mV} /$ s). Insets: SEM images of the SPE surface before and after modification; b: electrochemical polymerization of PANi on a Nafion/ $\mathrm{Cu}_{2} \mathrm{O}$-modified SPE $(0.2 \mathrm{M}$ aniline, $0.5 \mathrm{M} \mathrm{HCl}$, scan rate $50 \mathrm{mV} / \mathrm{s})$. Inset: SEM image of the SPE surface before and after modification; c: voltammetric responses of a modified SPE at different stages of assembly in neutral media (phosphate buffer, scan rate $50 \mathrm{mV} / \mathrm{s}$ ) electrode surface. Subsequent anodic sweep is characterized with the appearance of anodic peaks of current, which corresponds to the formation of $\mathrm{Cu}^{2+}$ ions from the adsorbed precursors. Continuous cycling led to an anodic shift of the observed peak, which indicated a change in the electrode surface properties. The backward scan shows the appearance of a reduction wave of metallic copper formation [6]. The change of electrode surface morphology due to modification was confirmed with SEM (Insets of Fig. 1a), while the transformation of chemical composition was observed with EDX (Fig. 1SB) and XPS (Fig. 2S). The pristine SPE surface exhibited high roughness. The uniform distribution of particles with diameters up to $100 \mathrm{~nm}$, as well as their aggregates, was visible on the modified SPE surface. The copper electrodeposition process was stopped at the cathodic limit, which corresponded to the presence of metallic copper on SPE surface. The presence of copper species was confirmed by XPS (Fig. 2S) and by visual observation as a color change from the mat black of pristine SPE, to the dark orange-brown of modified SPE and modified ITO-coated glass slides (data not shown).

As soon as the contact of $\mathrm{Cu}^{2+}$ ions with aniline causes the uncontrolled polymerization as manifested by the appearance of dark clouds in the bulk of solution (data not shown), the $\mathrm{Cu}_{2} \mathrm{O}$-modified electrode was covered with Nafion film by drop casting. The presence of the Nafion film ensured the stability of the composite-modified electrodes [13]. The Nafion coating provides a cation exchanger with immobilized sulfonate groups that impede the diffusion of anions. The redox processes of Nafion-coated PANi or polypyrrole films were shown to be accompanied by cation diffusion, as opposed to anion mass transport in the case of plain polyaniline or polypyrrole films which offers improved selectivity towards cations in the presence of anions $[13,16]$. After drying the film, the modified electrode was treated by electrochemical polymerization of PANi in aqueous acidic media (Fig. 1b). The anodic scan of the first cycle was characterized by a small and sharp peak of oxidation at $-0.12 \mathrm{~V}$, assigned to silver contamination from the integrated reference electrode, followed by a large peak of monomer oxidation at $0.9 \mathrm{~V}$. The backward scan was characterized by a nucleation loop, probably due to a new phase formation, followed by a broad reduction peak. Subsequent voltammetric cycling led to the appearance of two redox processes at $0.2 \mathrm{~V}$ and at $0.5 \mathrm{~V}$, indicated by a slight increase in the peak currents, which reflected the growth of composite PANi onto the Nafion-Cu-modified SPE, and was confirmed visually by a color change to dark green of the PANi-modified SPE. The electrode modification with PANi was confirmed by SEM (Inset of Fig. 2b), XPS (Fig. 3S) and EDX (Fig. 1SD).

Electrochemical polymerization on a copper-free Nafionmodified SPE led to the appearance of the 'classical' PANi voltammetry pattern (Fig. 4S), which was confirmed by SEM (Insets of Fig. 2S) and characterized by the same value of 

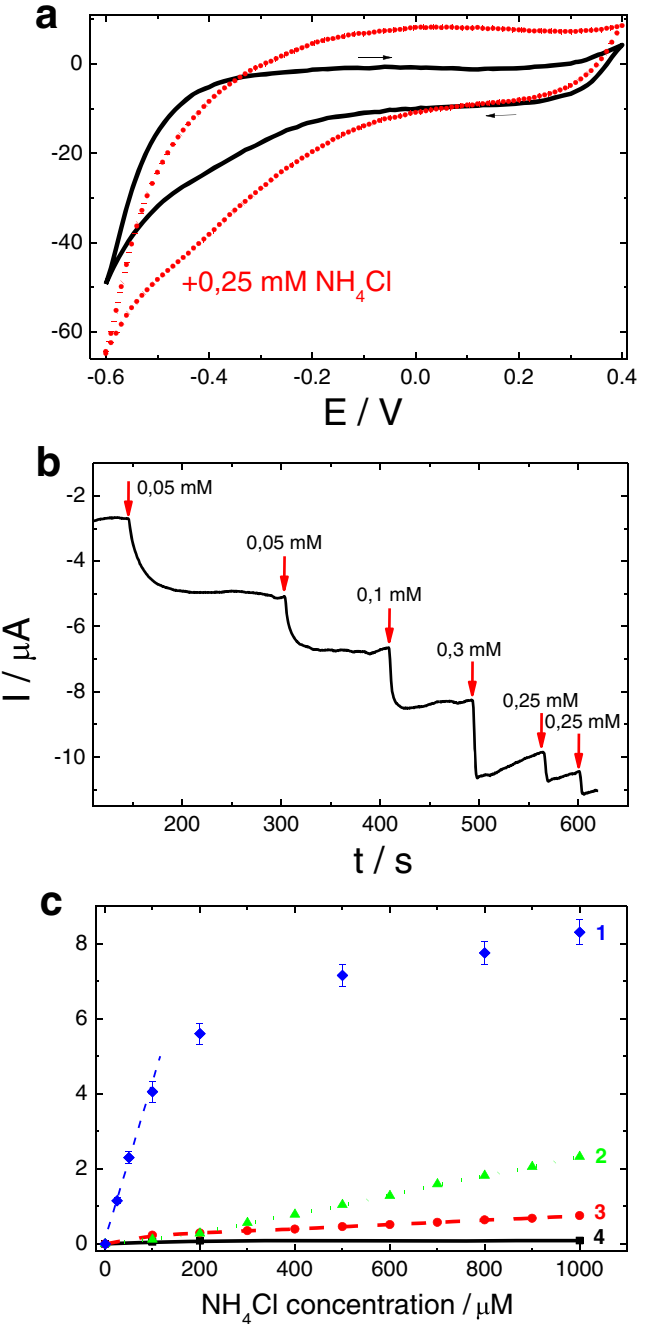

Fig. 2 Direct ammonium detection on a SPE modified with PANiNafion-Cu composite. a: Cyclic voltammograms recorded before and after addition of $0.25 \mathrm{mM} \mathrm{NH}_{4} \mathrm{Cl}$ (black and red curves, respectively; phosphate buffer, scan rate $50 \mathrm{mV} / \mathrm{s}$ ); b: an example of amperometric response of electrocatalyst to successive additions of $\mathrm{NH}_{4} \mathrm{Cl}(-0.45 \mathrm{~V}$, phosphate buffer); c: calibration curves for ammonium detection obtained at PANi-Nafion-Cu - (1), Cu- (2), PANi-Nafion-modified (3) and blank (4) SPE

surface-normalized integral charge $\left(13.5 \pm 2 \mathrm{mC} \mathrm{cm}^{-2}\right)$. The copper-free PANi had low sensitivity towards ammonium ions. The presence of copper during the PANi growth led to significant changes in the polymer properties. The first voltammetric forward scan during electropolymerization at a copper-modified SPE, produced up to six times larger currents in comparison with copper-free polymerization (Fig. 5S). This effect might be associated with the electrocatalytic polymerization of aniline initiated by $\mathrm{Cu}$ (II) and $\mathrm{Cu}$ (III) ions. These ions are strong non-specific oxidizers for organic molecules and always appear in the course of the oxidation of copper, as well as copper-containing modified electrodes, at high anodic potentials [4]. To this extent, the protocol of polymerization onto the copper-modified electrodes utilized opens up the possibility of PANi electropolymerization under conditions of catalysis by $\mathrm{Cu}$ (II) and $\mathrm{Cu}$ (III) ions.

The stepwise electrode modification was studied by voltammetry (Fig. 1c) and electrochemical impedance spectroscopy (EIS, Supporting Note 1) at pH 7.4. The copper-modified SPE showed the appearance of a sharp cathodic peak $(-0.47 \mathrm{~V})$ accompanied with a broad anodic peak $(-0.22 \mathrm{~V})$, assigned to copper deposition in the presence of the chloride anion [8] and a copper-stripping electrode process [25], respectively. An insignificant change in the electrode surface area during the first stage of the composite assembly was observed with EIS (Fig. 6S), which excludes mass transport enhancement of the subsequent electrochemical stage of assembly.

Subsequent electrode modification with a Nafion film led to the suppression of the cathodic peak current. This was attributed to copper deposition accompanied by a $150 \mathrm{mV}$ anodic shift (Fig. 1c), and a significant change in the capacitive properties of the SPE (Fig. 6SB), due to the decrease of local $\mathrm{pH}$ in the presence of the anionic polymer film. The PANimodified electrode showed full suppression of all electrode reactions, due to the poor conductivity of the polymer, in neutral media (Fig. 1c). However, the presence of Faradaic processes within the PANi leading to a further increase of capacitance is distinguishable with EIS. These observations illustrate the maintenance of low conductivity within the PANi-Nafion-Cu-composite at $\mathrm{pH} 7$, due to the Faradaic process of PANi.

\section{Amperometric ammonium ion sensing}

The addition of ammonium ions to the phosphate buffer lead to the appearance of a voltammetric response in the form of an increase in both the cathodic and anodic currents of the PANicomposite (Fig. 2a).

Amperometry at $-0.45 \mathrm{~V}$ was utilized for measurement of the response to an increase of ammonium concentration at the PANi-Nafion-Cu-modified electrode (Fig. 2b). A consistent increase in the cathodic current was observed as a result of increased ammonium ion concentration. An amperometric study in de-oxygenated buffer revealed only slight increases in the cathodic currents upon addition of ammonium ions (Fig. 7S), illustrating the involvement of oxygen in the observed cathodic currents via ORR electrocatalysis and pointing out the possible limitation of the method as a response dependence on oxygen content. This phenomenon facilitated the elucidation of the mechanism behind the observed amperometric response. Cathodic polarization up to $-0.7 \mathrm{~V}$ led to the appearance of a copper deposition peak (data not shown) facilitated by chloride anions [8]. The lower cathodic polarization $(-0.45 \mathrm{~V})$ used for the amperometry measurements leads to the appearance of species containing $\mathrm{Cu}$ (I) [9]. The addition of ammonium ions resulted in the formation 
$\mathrm{NH}_{4}^{+} \rightleftarrows \mathrm{NH}_{3}+\mathrm{H}^{+}$

$\mathrm{Cu}^{+}+2 \mathrm{NH}_{3} \rightleftarrows\left[\mathrm{Cu}\left(\mathrm{NH}_{3}\right)_{2}\right]^{+}$

$2\left[\mathrm{Cu}\left(\mathrm{NH}_{3}\right)_{2}\right]^{+}+1 / 2 \mathrm{O}_{2}+3 \mathrm{H}_{2} \mathrm{O}+2 \mathrm{H}^{+} \longrightarrow 2\left[\mathrm{Cu}\left(\mathrm{NH}_{3}\right)_{2}\left(\mathrm{H}_{2} \mathrm{O}\right)_{2}\right]^{2+}$

$\left[\mathrm{Cu}\left(\mathrm{NH}_{3}\right)_{2}\left(\mathrm{H}_{2} \mathrm{O}\right)_{2}\right]^{2+}+\mathrm{e}^{-} \longrightarrow\left[\mathrm{Cu}\left(\mathrm{NH}_{3}\right)_{2}\right]^{+}+2 \mathrm{H}_{2} \mathrm{O}$

Scheme 1 The ORR at the $\mathrm{Cu}(\mathrm{I})$-based PANi composite in the presence of ammonia

of a complex between $\mathrm{Cu}(\mathrm{I})$ and neutral ammonia $\left(\mathrm{pK}_{\mathrm{a}} 9.24\right)$, which is easily oxidized by dissolved oxygen to $\mathrm{Cu}$ (II) [17] with subsequent electrochemical reduction back to $\mathrm{Cu}$ (I), observed as a cathodic current increase. Four electron reduction of oxygen down to water [2] illustrates the high reactivity of the $\mathrm{Cu}(\mathrm{I})$-based catalyst. In other words, ammonia complex formation triggers an ORR at the $\mathrm{Cu}$ (I)-based species, which in turn, acts to enhance the binding. The whole process is explained in terms of ammonia-associated ORR electrocatalysis, as illustrated in Scheme 1.

EIS studies of the observed ammonium response of PANiNafion-Cu-modified electrodes did not show a significant change in the film conductivity (data not shown), which excludes the possibility of additional doping of PANi by the proton released due to the neutral ammonia complex formation, and supports the faradaic origin of the amperometric response observed. However, the complete mechanism underlying the high sensitivity of the $\mathrm{Cu}$ (I)-based catalyst towards ammonium ions is still unclear and the role of PANi and Nafion in this process should be further investigated.

Due to the Faradaic origin of the response obtained at the electrocatalyst, only a slight $\mathrm{pH}$ effect was observed (Fig. 8S), which shows the advantage of direct quantification in comparison with potentiometric ammonium ion electroanalysis, which is significantly affected by $\mathrm{pH}$ changes.

The analytical performance of the ammonium sensor was evaluated and showed good operational stability. Fast changes

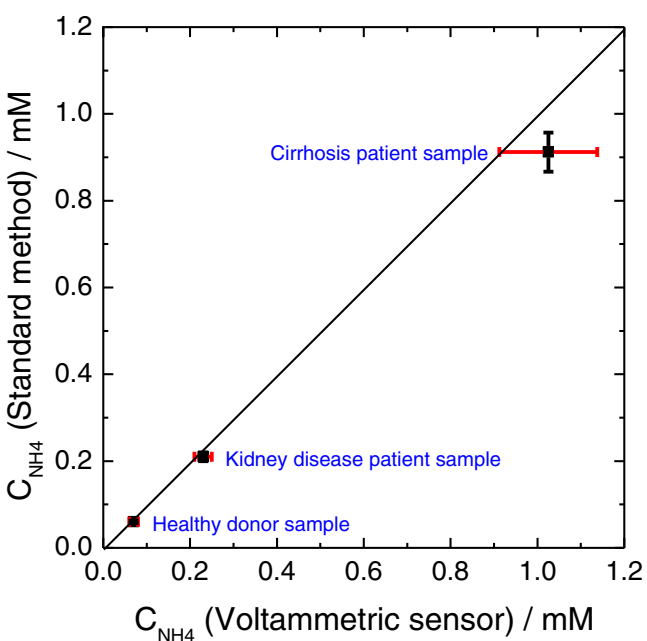

Fig. 3 Comparative ammonium quantification in human serum. The ammonium ions concentration was estimated by the amperometry with the sensor and by the standard spectroscopy-based method

in current upon ammonium concentration increase were preceded by a slow component for 20-30 s, until a steady-state current was achieved. The calibration curve obtained from amperometry at PANi-Nafion-Cu-modified electrodes under optimized conditions showed a linear range from 1 to $150 \mu \mathrm{M}$, a sensitivity value within the linear range of $250 \pm 10 \mathrm{~mA} \mathrm{M}^{-1} \mathrm{~cm}^{-2}$ and a dynamic range $1-1000 \mu \mathrm{M}$ (Fig. 2c). The limit of detection assessed as $3 \times \mathrm{SD} /$ sensitivity, was $0.5 \mu \mathrm{M}$. The electrode surface modification delivered high reproducibility as measured by the response of the individual sensors. The sensor had high stability, demonstrated by $95 \%$ retention of sensitivity over one year of storage at room temperature. Subsequent washing with pure buffer led to the recovery of the observed electrocatalytic activity. This is consistent with the entrapment of the inorganic electrocatalyst via

Table 1 Analytical characteristics of different ammonium ion electrochemical sensors

\begin{tabular}{|c|c|c|c|c|}
\hline & Signal registration mode and sensing component & $\mathrm{LOD} \mu \mathrm{M}$ & Linear range $\mu \mathrm{M}$ & Sensitivity, $\mathrm{mA} \mathrm{M}^{-1} \mathrm{~cm}^{-2}$ \\
\hline \multirow[t]{4}{*}{ Potentiometry } & Asymmetric type polyurethane membrane with immobilized nonactin [19] & 1 & $10-1 \times 10^{5}$ & - \\
\hline & ISFET* based on a zeolite incorporated polymeric membrane [10] & 15 & $15-1 \times 10^{4}$ & - \\
\hline & ISFET based on a siloprene including clinoptilolite [11] & 0.01 & $15-1 \times 10^{4}$ & - \\
\hline & Photocured poly(n-butyl acrylate) membrane with immobilized nonactin [12] & 1 & $10-1 \times 10^{5}$ & - \\
\hline \multirow[t]{8}{*}{ Amperometry } & NAD(P)H detection, catalyzed by GLDH** on platinum electrode [3] & 10 & $10-3 \times 10^{2}$ & - \\
\hline & $\begin{array}{l}\text { NADH detection, catalyzed by GLDH, mediated with Meldola's } \\
\text { Blue on SPE [1] }\end{array}$ & 1.7 & $1.7-2.5 \times 10^{2}$ & 1.33 \\
\hline & $\mathrm{PANi} / \mathrm{Pt}$ on graphite SPE [22] & 5 & $5-1 \times 10^{3}$ & $40 \pm 20$ \\
\hline & PANi-Nafion on GCE*** [7] & 5 & $10-2 \times 10^{2}$ & $7 \pm 0.3$ \\
\hline & PANi-Nafion on gold electrode [15] & 83 & $83-1.68 \times 10^{3}$ & $155 \pm 6$ \\
\hline & Cyclodextrin $[18]$ & 0.12 & $4.2-0.66 \times 10^{2}$ & - \\
\hline & PANi-Nafion on platinum electrode [21] & 5.35 & $5-1.25 \times 10^{3}$ & $11 \pm 0.1$ \\
\hline & PANi-Nafion/ $\mathrm{Cu}_{2} \mathrm{O} / \mathrm{SPE}$, this work & 0.5 & $1-1.5 \times 10^{2}$ & $250 \pm 10$ \\
\hline
\end{tabular}

*ammonium ion-selective field effect transistor; ** glutamate dehydrogenase; *** glassy carbon electrode 
a stable complex formation within the polymer environment and probably a smaller stoichiometric ratio between oxygen and ammonia, than presented in the Scheme 1.

Both the Cu-modified SPE and the copper-free PANi composite showed significantly lower sensitivities for electrochemical ammonium ion detection $\left(18.4 \pm 1.4 \mathrm{~mA} \mathrm{M}^{-1} \mathrm{~cm}^{-2}\right.$ and of $5.95 \pm 0.8 \mathrm{~mA} \mathrm{M}^{-1} \mathrm{~cm}^{-2}$ respectively), which illustrates the crucial contributions of all the components in the active electrocatalyst assembly.

Comparison of the analytical performance of the ammonium ion sensor with systems described in the literature (Table 1S) shows that the sensor possesses several advantageous characteristics. It provides a combination of the highest sensitivity with one of the lowest limits of detection and has a wide linear range that meets the requirements for an assay for ammonium levels in humans.

The effects of some possible interfering biological compounds on the elaborated ammonium sensor were also investigated (Fig. 9S). The amperometric responses to ammonium ion showed $4-5 \%$ retention in the presence of $0.1 \%$ BSA in phosphate buffer. The excessive presences of model primary amines (creatinine $\left(\mathrm{pK}_{\mathrm{a}} 5.02\right)$, urea $\left(\mathrm{pK}_{\mathrm{a}} 0.1\right)$ and their mixtures) showed negligible response (significance level $5 \%$ ), which, probably, illustrates the composite selectivity towards cations (Table 1).

\section{Real sample analysis}

The ammonium ion sensor was used for the quantification of ammonium in serum samples of healthy donors, cirrhosis and kidney disease patients. Ammonium ion concentrations were measured using the standard addition method (Fig. 10S) with different SPEs modified with the PANi-Nafion-Cu composite ( $\mathrm{RSD}=4 \%$ for $n=3)$. The data obtained showed a good correlation $(R=0.999)$ with the standard method for ammonium measurement based on spectroscopy (Fig. 3) with an RSD of $1 \%$. The ammonium ion concentration in serum of healthy donors was 3.5 and 15 times lower than in the serum of kidney disease and cirrhosis patients, respectively. The results obtained demonstrate the potential of this ammonium sensor for measurements in serum and the possibilities for further development of analytical devices for distributed diagnostics and environmental analysis.

\section{Conclusions}

An amperometric sensor for ammonium quantification has been elaborated using an ORR catalyst based on PANi in combination with copper. The electrochemical polymerization of PANi, in the presence of copper ions attached to the electrode surface by Nafion membrane, yielded a polymer composite sensitive to ammonium ions, which was characterized via electrochemical and physical methods. The specific amperometric response to ammonium ions observed at the composite-modified electrode was attributed to ammoniaassociated ORR catalyzed by copper centers within the film. The sensor exhibited enhanced analytical performance over previously reported devices and was successfully utilized for ammonium quantification in human serum samples.

Acknowledgments This work was partially funded by the "SMARTCANCERSENS" project from the European Community Seventh Framework Program under the Grant Agreement PIRSES-GA2012-318053 and by the NATO Science for Peace (SFP) Project CBP.NUKR.SFPP 984173. Authors would like to thank also Dr. Olga Beloivan and Mr. Krishnakumar Pillai for SEM and EDX measurements.

Compliance with ethical standards The author(s) declare that they have no competing interests

\section{References}

1. Abass AK, Hart JP, Cowell DC, Chappell A (1998) Development of an amperometric assay for $\mathrm{NH}^{+}$based on a chemically modified screen-printed NADH sensor. Anal Chim Acta 373:1-8

2. Annamalai SK, Palani B, Pillai KC (2012) Highly stable and redox active nano copper species stbilized functionalized-multiwalled carbon nanotube/chitosan modified electrode for efficient hydrogen peroxide reduction. Colloids Surf A Physicochem Eng Asp 395: 207-216

3. Bertocchi P, Compagnone D, Palleschi G (1996) Amperometric ammonium ion and urea determination with enzyme-based probes. Biosensors \& Bioelectronics 11:1-10

4. Burke LD, Ahern MJG, Ryan TG (1990) An investigation of the anodic behaviour of copper and its anodically produced oxides in aqueous solutions of high pH. J Electrochem Soc 137:553-561

5. Cho WJ, Huang HJ (1998) An amperometric urea biosensor based on a polyaniline-perfluorosulfonated ionomer composite electrode. Anal Chem 70:3946-3951

6. Davis J, Moorcroft MJ, Wilkins SJ, Compton RG, Cardosi MF (2000) Electrochemical detection of nitrate and nitrite at a copper modified electrode. Analyst 125:737-741

7. Deng AP, Cheng JT, Huang HJ (2002) Application of a polyaniline based ammonium sensor for the amperometric immunoassay of a urease conjugated Tal 1 protein. Anal Chim Acta 461:49-55

8. Fogg AG, Scullion SP, Edmonds TE, Birch BJ (1991) Direct reductive amperometric determination of nitrate at a copper electrode formed $\ln$ situ In a capillary-fill sensor device. Analyst 116:573-579

9. Giannopoulou I, Panias D, Paspaliaris I (2009) Electrochemical modeling and study of copper deposition from concentrated ammoniacal sulfate solutions. Hydrometallurgy 99:58-66

10. Hamlaoui ML, Kherrat R, Marrakchi M, Jaffrezic-Renault N, Walcarius A (2002) Development of an ammonium ISFET sensor with a polymeric membrane including zeolite. Materials Science \& Engineering C-Biomimetic And Supramolecular Systems 21:25-28

11. Hamlaoui ML, Reybier K, Marrakchi M, Jaffrezic-Renault N, Martelet C, Kherrat R, Walcarius A (2002) Development of a urea biosensor based on a polymeric membrane including zeolite. Anal Chim Acta 466:39-45 
12. Heng LY, Alva S, Ahmad M (2004) Ammonium ion sensor based on photocured and self-plasticising acrylic films for the analysis of sewage. Sensors and Actuators B-Chemical 98:160-165

13. Hirai T, Kuwabata S, Yoneyama H (1988) Electrochemical behaviors of polypyrrole, poly-3-methylthyophene and polyaniline deposited on nafion-coated electrodes. J Electrochem Soc 135:1132-1137

14. Lockwood AH, McDonald JM, Reiman RE, Gelbard AS, Laughlin JS, Duffy TE, Plum F (1979) Dynamics of ammonia metabolism in man - effects of liver-disease and hyper-ammonemia. J Clin Investig 63:449-460

15. Luo YC, Do JS (2004) Urea biosensor based on PANi(urease)Nation (R)/Au composite electrode. Biosensors \& Bioelectronics 20:15-23

16. Nagasubramanian G, Distefano S, Moacanin J (1986) Electrochemical incorporation of poly(pyrrole) into nafion and comparison of the electrochemical properties of nafion poly(pyrrole) Amd poly(pyrrole) film. J Phys Chem 90:4447-4451

17. Nicholls D (1973) Complexes and first-Row transition elements. Macmillan Press, London

18. Ribeiro JA, Silva F, Pereira CM (2012) Electrochemical sensing of ammonium ion at the water/1,6-dichlorohexane interface. Talanta 88:54-60

19. Shin JH, Yoon SY, Yoon IJ, Choi SH, Lee SD, Nam H, Cha GS (1998) Potentiometric biosensors using immobilized enzyme layers mixed with hydrophilic polyurethane. Sensors and Actuators BChemical 50:19-26

20. Silva R, Voiry D, Chhowalla M, Asefa T (2013) Efficient metal-free electrocatalysts for oxygen reduction: polyaniline-derived $\mathrm{N}$ - and O-doped mesoporous carbons. JACS 135:7823-7826
21. Stasyuk N, Smutok O, Gayda G, Vus B, Koval'chuk Y, Gonchar M (2012) Bi-enzyme L-arginine-selective amperometric biosensor based on ammonium-sensing polyaniline-modified electrode. Biosensors \& Bioelectronics 37:46-52

22. Strehlitz B, Grundig B, Kopinke H (2000) Sensor for amperometric determination of ammonia and ammonia-forming enzyme reactions. Anal Chim Acta 403:11-23

23. Thompson M, Krull UJ, Bendellyoung LI (1983) The bilayer lipidmembrane as a basis for a selective sensor for ammonia. Talanta 30 : 919-924

24. Vanson M, Schothorst RC, Denboef G (1983) Determination of total ammoniacal nitrogen in water by flow-injection analysis and a gas-diffusion membrane. Anal Chim Acta 153: 271-275

25. Vazquez-Arenas J, Lazaro I, Cruz R (2007) Electrochemical study of binary and ternary copper complexes in ammonia-chloride medium. Electrochim Acta 52:6106-6117

26. Vitousek PM, Aber JD, Howarth RW, Likens GE, Matson PA, Schindler DW, Schlesinger WH, Tilman D (1997) Human alteration of the global nitrogen cycle: sources and consequences. Ecol Appl 7:737-750

27. Whittingham MS, Zawodzinski T (2004) Introduction: batteries and fuel cells. Chem Rev 104:4243

28. Winther-Jensen B, Winther-Jensen O, Forsyth M, Macfarlane DR (2008) High rates of oxygen reduction over a vapor phasepolymerized PEDOT electorde. Science 321:671

29. Yuan Y, Ahmed J, Kim S (2011) Polyaniline/carbon black composite-supported iron phtalocyanine as an oxygen reduction catalyst for microbial fuel cell. J Power Sources 196:1103 